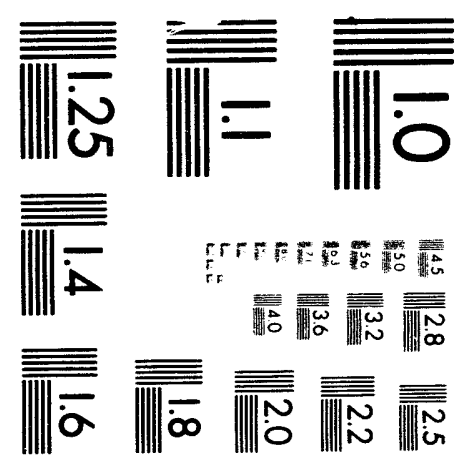



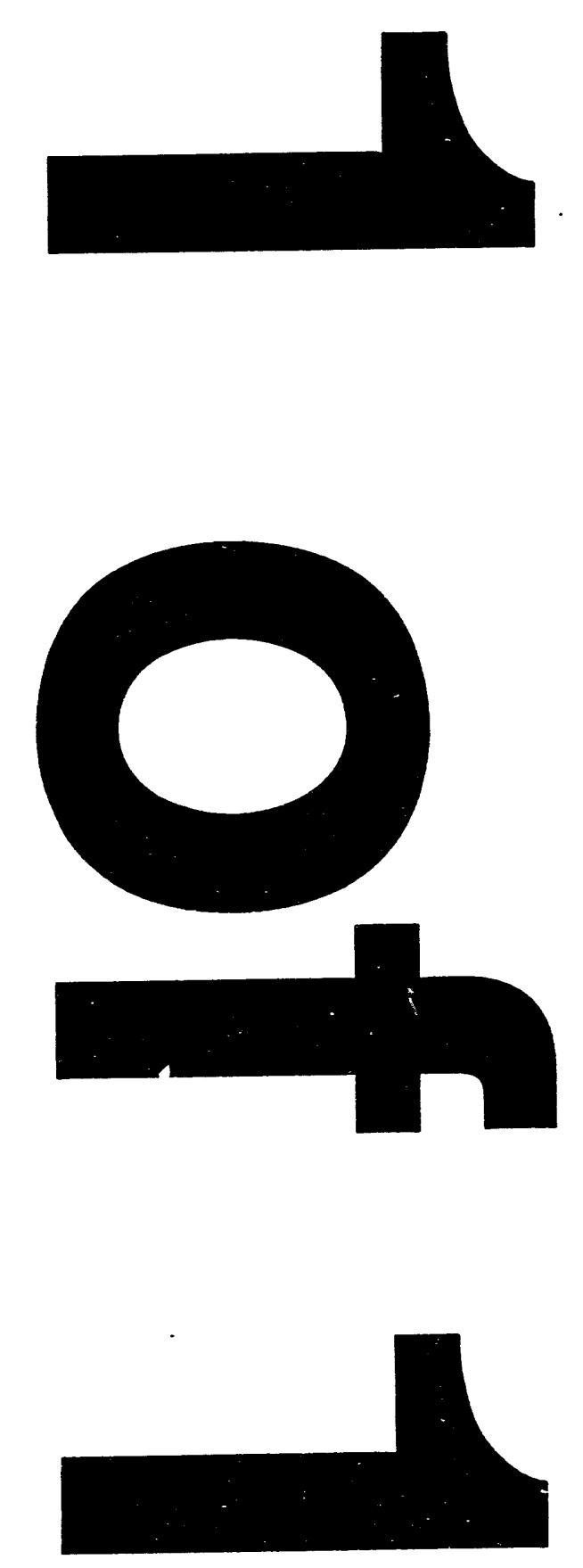
M. YAMADA, F.M. LEVINTON, J. MANICKAM, ET AL.

JANUARY, 1994
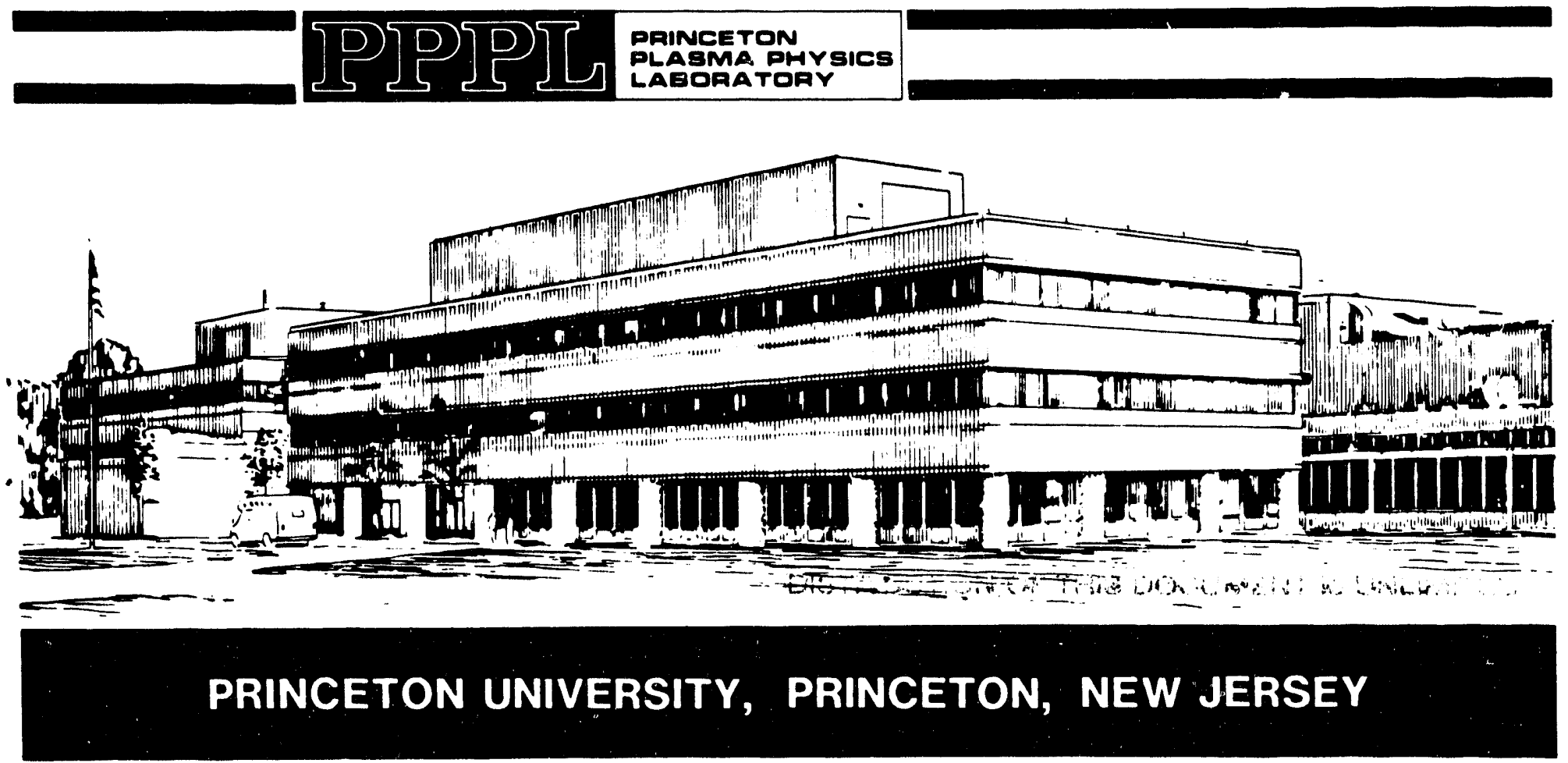


\section{NOTICE}

This report was prepared as an account of work sponsored by an agency of the United States Government. Neither the United States Government nor any agency thereof, nor any of their employees, makes any warranty, express or implied, or assumes any legal liability or responsibility for the accuracy, completeness, or usefulness of any information, apparatus, product, or process disclosed, or represents that its use would not infringe privately owned rights. Reference herein to any specific commercial produce, process, or service by trade name, trademark, manufacturer, or otherwise, does not necessarily ccnstitute or imply its endorsement, recommendation, or favoring by the United States Government or any agency thereof. The views and opinions of authors expressed herein do not necessarily state or reflect those of the United States Government or any agency thereof.

\section{NOTICE}

This report has been reproduced from the best available copy.

Available in paper copy and microfiche.

Number of pages in this report: 17

DOE and DOE contractors can obtain copies of this report from:

Office of Scientific and Technical Information

P.O. Box 62

Oak Ridge, TN 37831;

(615) $576-8401$.

This report is publicly available from the:

$$
\begin{gathered}
\text { National Technical Information Service } \\
\text { Department of Commerce } \\
5285 \text { Port Royal Road } \\
\text { Springfield, Virginia } 22161 \\
\text { (703) } 487-4650
\end{gathered}
$$




\title{
Experimental Study of Magnetic Reconnection during a Sawtooth Crash in a High Temperature Tokamak Plasma
}

by

\author{
M. Yamada, F.M. Levinton*, J. Manickam, Y. Nagayama**, and N. Pomphrey \\ Princeton Plasma Physics Laboratory, Princeton University \\ P.O. Box 451, Princeton, NJ 08543 USA
}

\begin{abstract}
Magnetic reconnection is investigated in high temperature TFTR tokamak plasmas by a set of non-perturbative diagnostics. During the crash phase of sawtooth oscillations in the plasma discharges, the ECE (electron cyclotron emission) diagnostic measures a fast flattening of the 2-D electron temperature profile in a poloidal plane, an observation consistent with the Kadomtsev reconnection theory. On the other hand motional Stark effect(MSE) measurements indicate that central q values do not relax to unity after the crash, but increase only by $5-10 \%$, typically from 0.7 to 0.75 . The latter result is in contradiction with the models of Kadomtsev and/or Wesson. A heuristic model for the magnetic reconnection at the sawtooth crash is also presented.
\end{abstract}

*Fusion Physics and Technology Torrance, CA 90503

**University of Tsukuba, Japan

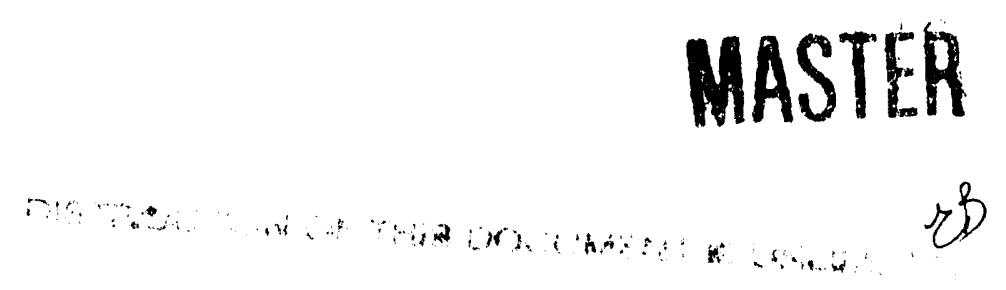


Magnetic reconnection, which involves the breaking and topological rearrangement of magnetic field lines, occurs as one of the relaxation processes in fusion research plasmas ${ }^{1}$. It also plays an important role in determining the confinement characteristics of high temperature fusion plasmas, and often manifests itself through sawtooth oscillations. Magnetic reconnection is also considered to be a key process in the description of the evolution mechanisms for solar flares ${ }^{2}$, the earth's magnetosphere 3 and some low temperature laboratory experiments 4,5 .

The primary subject of the present paper is an experimental study of the magnetic reconnection in high temperature TFTR tokamak plasmas, where the Magnetic Reynolds number exceeds $10^{7}$, by a set of non-perturbative diagnostics. During the crash phase of sawtooth oscillations in the plasma discharges, ECE (electron cyclotron emission) and other diagnostic systems observe that the temperature gradient inside the inversion radius diminishes to nearly zero after the crash. This observation is apparently consistent with the Kadomtsev 7 model. On the other hand, the $q$ profiles $(q(R)=$ local safety factor 6 ) measured by motional Stark effect (MSE) diagnostics indicate that central q values increase by $5-10 \%$, typically from 0.7 to 0.75 , during the sawtooth crash phase but do not relax to unity even while the pressure gradient diminishes inside the $q=1$ region. This latter result is an important contradiction with the theories of Kadomtsev 7 and Wesson 8 .

The present paper addresses this puzzle by a simultaneous analysis of electron temperature and $\mathrm{q}$ profile evolutions. Small changes of $\mathrm{q}$ profile are documented. Based on a heuristic model for the magnetic reconnection during the sawtooth crash, the small change of q values is attributed to flux conservation plasma dynamics as well as to the precipitous drop of pressure gradients which drive the instability and the reconnection process. 
A sawtooth oscillation, which is frequently observed as a relaxation cycle in tokamak discharges $6-8$, is characterized by a periodic collapse or crash of the central plasma pressure. The crash phase of the sawtooth can manifest important physics mechanisms for magnetic reconnection, since field line re-arrangement is expected during this period 7,8 . Although there are several theoretical models for the sawtooth, Kadomtsev's model ${ }^{7}$ developed twenty years ago has attained the widest acceptance. According to this model an $m=n=1$ resistive internal mode (where $\mathrm{m}$ and $\mathrm{n}$ are the poloidal and toroidal mode numbers) is unstable for $\mathrm{q}_{0}(\mathrm{q}$ at magnetic axis) $<1$ and grows until a full magnetic reconnection process flattens the pressure and current profiles causing the central q value to increase to unity.

The electron temperature evolution has been studied during sawtoothing TFTR discharges with simultaneous ECE and Soft-Xray tomographies $10,11$. However, a full documentation of sawtooth oscillation has had to wait for experimental measurement of $q(R)$, the safety factor profile. The present MSE diagnostic has sufficient accuracy and spatial and temporal resolution to measure detailed $q(R)$ evolution 9 .

The electron temperature profile on the midplane of the plasma is measured with a 20 channel grating polychrometer and with a $2 \mu$ s time step covering $R=2.1$ - $3.4 \mathrm{~m}$ with a spatial channel separation of $6 \mathrm{~cm}$. Figure 1 depicts a typical $\mathrm{Te}(\mathrm{R})$ profile evolution during the sawtooth crash. It is observed that elecuron heat transfer is predominantly localized from the inside to just outside of the inversion radius ( $\left.\mathbf{r}_{\mathbf{q}=1}\right) 10,11$. The electron density is observed to flatten on a $\operatorname{similar}(\sim 200 \mu \mathrm{sec}$. $)$ time scale. The ion temperature is also observed to flatten after the crash although the time resolution of the $\mathrm{T}_{\mathrm{i}}$ diagnostic is as long as $50 \mathrm{msec}$.

A 2D electron temperature profile can be produced by translating the fast toroidal rotation of the plasma on a poloidal plane 10 . The present work extends this 
2-D imaging technique further to elucidate the electron heat flow pattern during sawtooth oscillations. If we define the difference of the electron temperature profile as $\Delta \mathrm{T}_{\mathrm{e}}(\mathrm{r}, \theta)=\mathrm{T}_{\mathrm{e}}(\mathrm{r}, \theta)-\operatorname{Min}\left[\mathrm{T}_{\mathrm{e}}(\mathrm{r}, \theta)\right]$, we can visually describe an inventory of the excess electron thermal energy during the sawtooth period. Here, $\operatorname{Min}[\mathrm{Te}(\mathrm{r}, \theta)]$ is the lowest value of $\mathrm{T}_{e}(r, \theta, t)$ at the location $r, \theta$ at any time during a sawtooth cycle. Overlaying color contours of $\Delta \mathrm{T}_{\mathrm{e}}$ on the $3 \mathrm{D}-\mathrm{T}_{\mathrm{e}}(\mathrm{r}, \theta)$ profile allows one to visualize 11 a transfer of an excess electron heat during the crash period as shown in Fig. 1. Just before the crash, a shrinking circular hot peak and a growing crescentshaped flat island region 17 appear inside the inversion radius. The $T e$ profile inside the inversion radius is nearly flat after the crash. The spatial $(<6 \mathrm{~cm})$ and time $(\sim 10 \mu \mathrm{sec})$ resolutions of this representaion were dicussed with description of the image reconstruction techniques in the previous publications 10,11 .

To describe the electron heat flow pattern semi-quantitatively on a poloidal plane, we approximated a time derivative of the electron temperature profile as

$$
\delta \mathrm{T}_{\mathrm{e}}(\mathrm{r}, \theta, \mathrm{t}) / \delta \mathrm{t}=\left[\mathrm{Te}(\mathrm{r}, \theta, \mathrm{t}+\tau)-\mathrm{T}_{\mathrm{e}}(\mathrm{r}, \theta, \mathrm{t})\right] / \tau,
$$

where, $\tau$ is the plasma's toroidal rotation period, typically $50 \mu \mathrm{sec}$, which is usually much shorter than the crash phase period. Fig.2 shows color contours of $\delta \mathrm{T}_{\mathrm{e}}(\mathrm{r}, \theta, \mathrm{t}) / \mathrm{ot}$ overlayed on $\mathrm{T}_{\mathrm{e}}(\mathrm{r}, \theta)$ contours(solid lines), depicting the transfer of electron heat during the sawtooth crash. The entire crash phase is takes $150-800$ $\mu \mathrm{sec}$, while a sawtooth period is $100-200 \mathrm{msec}$. In Fig.2(a)\&(b) one can recognize a heat flow around the circular hot region from inside to outside towards the intersection(X-point) of the hot circle with the $q=1$ surface. Fig.2(c)\&(d) show that the heat is eventually transfered to the outside of $q=1$ (shown as a dashed line). It is expected that magnetic reconnection causes this anomalous heat flow. The fast radial electron heat transport outside of the $\mathrm{q}=1$ radius was studied during and after the crash as a heat pulse propagation 13 . 
We employ the motional Stark effect diagnostic to obtain the profile of magnetic pitch angle, and hence the q profile, using polarimetry measurements of the Doppler shifted $\mathrm{D}_{\alpha}$ emission from a neutral deuterium--beam (NBI) heating line 14,9. An important advantage of this technique is that the nonperturbative measurement of the field-line pitch is localized to the geometric intersection of the field of view with the neutral beamlines, which leads to good spatial resolution of $\delta \mathrm{r}=3 \sim 5 \mathrm{~cm}$. The time resolution is as short as $5 \mathrm{msec}$ but typically $10 \mathrm{msec}$. If the plasma is considered to have good flux surfaces, the measured field line pitch can be translated into a radial profile of rotational transform, or $q(R)$ profile, based on tokamak equilibrium calculations. The assumption of good flux surfaces is valid for the $\mathrm{q}(\mathrm{r})$ calculation during the entire sawtooth period $(\sim 100 \mathrm{msec})$ except for the fast crash phase $(<1 \mathrm{msec})$ which is unresolved by the present MSE measurements.

The relationship of magnetic field pitch angle to the $\mathrm{q}(\mathrm{R})$ profile depends on the configuration (aspect ratio, $a / R$, elongation, triangularity) and on plasma parameters such as poloidal beta and internal plasma inductance 15 . For tokamak plasmas with nested nearly circular flux surfaces, large aspect ratio and modest beta, the safety factor may be approximated as

$$
q(\rho)=\frac{\rho}{R_{\operatorname{mag}}} \frac{1}{\tan \gamma_{p}\left(1+\partial \Delta_{S} / \partial \rho\right)}
$$

where $\Delta_{S}=\frac{a_{S}{ }^{2}-\rho^{2}}{2 R_{\text {mag }}}\left(l_{i} / 2+\beta_{p}\right)$ is the Shafranov shift of each flux surface, as is the effective minor radius of the plasma, $\rho$ the radius of each flux surface, $R_{\text {mag }}$ the major radius of the magnetic axis, $l_{i}$ the internal plasma inductance, $\beta_{p}$ the poloidal beta and $\tan \gamma_{p}(R)=\frac{B_{p}(R)}{B_{t}(R)}$ define the magnetic pitch angle. In the present experiment we measure the pitch angle of the magnetic field from inboard of the magnetic axis to near the outboard edge of the plasma. For $R<R_{m a g}, E q(2)$ 
should be modified by changing the sign of $\partial \Delta_{\mathrm{S}} / \partial \rho$. $E q(2)$ is valid only for $\varepsilon \beta_{p}<$ 1 , and has been shown to be accurate to within $5 \%$ for $\rho \beta_{\mathrm{p}} / R_{\operatorname{mag}}<0.5$ using the PEST equilibrium code.

The $q$ profiles before and after the sawtooth crash have been examined for typical neutral beam heated $(\mathrm{Pb}=8-11 \mathrm{MW}$ ) TFTR plasmas with toroidal current of 1.8 MA. Fig. 3 presents typical $q(R)$ profiles before and after a sawtooth crash. The statistical error in the calculated q value is estimated to be less than $2.5 \%$, although the systematic error is evaluated to be about $5 \%$ for $q(R)$ data based on a comparative analysis with the ECE inversion radii and by radially moving the magnetic axis 9 . About two dozen similar discharges have been investigated and the central q values do not relax to unity after the crash, but increase only by $5-10 \%$, typically from 0.7 to 0.75 by $7-10 \%$ during the crash with a relative error of $2 \%$. This observation is in agreement with the earlier result from TEXTOR 12 based on a far infrared (FIR) polarimetry.

Fig.4(a) pre:ents time evolution of central q values from MSE and the central electron temperature from the ECE signals in a typical sawtooth discharge. Correlated with the sawtooth collapse is a small rise of $\sim 0.08$ for q0. In this example, as well as most TFTR discharges, q0 is below one when sawteeth are present, and remains below unity throughout the sawtooth cycle. In order to reduce the statistical uncertainty and improve the time resolution, which is $30 \mathrm{~ms}$ for the data shown here, we can synchronously or co-average the data over several sawteeth as shown in Fig.4(b). Because only field-line breaking and re-arrangement can make a $\mathrm{q}(\mathrm{R})$ change on such a short time scale ( $<$ magnetic diffusion time), the observations verify a magnetic field-line reconnection, albeit small.

The observations raise the critical question as to why the magnetic field lines inside the $q=1$ region do not form a flat $q \sim 1$ inner region after the crash as suggested by Kadomtsev 7 , while the temperature gradient diminishes to zero as 
predicted by him for full reconnection. The clues to answering this question lie in the heat flow pattern shown in Fig. 2 during the crash phase, which vccurs in a very short time as a result of a violent kink instability with $m / n=1 / 1$. The heat flow is observed to be the largest in the 'reconnection' region/reddish colored spots in Fig2.(a) and(b)] located just outside the non-axisymmetric hot $T_{e}$ contours.

We propose a model in which the plasma is viewed as concentric toroidal regions separated by the $q=1$ surface. The $m / n=1 / 1$ kink instability is primarily confined to the inner region while the outer region plays the role of a stable conducting shell. The kink mode displaces the pressure contours on an ideal MHD time scale with a helical(1/1) structure, Fig.1\&2. In the final stage, the pressure contours will be displaced more than the magnetic flux surfaces 16 (the plasma pressure is not constant on a flux surface). The external conducting region tries to suppress the flux displacement by inducing image currents near the interface of the two regions, often called an "X-point". In the common picture 2,3 , the image currents are called neutral sheet currents, and their diffusion causes a magnetic reconnection. A fast reconfiguration of magnetic field lines occurs connecting the inner region of the plasma to the outside through the X-point region. A rapid efflux of thermal energy occurs through the X-point region along newly connected field lines, as observed in Fig.2. The precipitous drop of the pressure gradient,which occurs within a short period of $100-200 \mu \mathrm{sec} \mid<<\tau_{\text {Sweet-Parker }}{ }^{2,7}$ ], removes the free energy to drive the $m / n=1 / 1$ instability, inhibiting further progress of the mode and thus full reconnection.

The gradient drop should induce a decrease in the central current density or q profile. Such a change would be associated with a decrease in the internal plasma inductance, $\mathrm{l}_{i}$, due to the expulsion of poloidal flux from the inner plasma regime. However, in a conductive plasma, flux conservation will also inhibit a radical 
change of the current profile and prevent the Kadomtsev type total mixing of field lines ["complete reconnection"] to form $q=1$ inner region. We note that there are multiple solutions for $j(R)$ which satisfy $\mathbf{j} \times \mathbf{B}=0$ for $q<1$, if $\mathbf{j} \cdot \mathbf{B} / \mathrm{B}^{2}$ is not constant ${ }^{1}$ with respect to $R$. Consequently, the amount of the $q(R)$ change can be small, and $\mathrm{q}_{0}$ does not have to rise to unity for $\nabla \mathrm{p} \sim 0$.

Evolution of central q values have been measured by several groups in the past few years $12,18,19$. There is agreement among all experiments that the relative change of the central $q$ values during a sawtooth crash is $\operatorname{small}(\Delta q / q \leq 0.1)$. However, there is a major difference among the experiments on the final values of the central q after the crash. Wroblewski and Snider 19 recently reported that the central $\mathrm{q}$ values rise to 1 concluding that the observation is evidence of the Kadomtsev reconnection. Although the cause of the apparent disagreement is yet to be determined, it could be attributed to, 1) difficulties in $q(R)$ measurements and their analysis as noted by Ref.19, and/or 2) DIII-D generates non circular plasmas 19 with different MHD properties from circular TFTR plasmas. We also note that the most results that reported $\Delta q<0.1$ during sawtooth crash can be explained by our proposed model.

Stability issues of the $\mathrm{m} / \mathrm{n}=1 / 1$ mode for the measured q profiles are presently being investigated, but are beyond the scope of the present paper which focuses on magnetic reconnection.

In summary, a magnetic reconnection has been verified as small but finite during a sawtooth crash, and changes of q profile are documented. It is shown that the $q$ values stay substantially below 1 , despite $T_{e}$ contour evolution from ECE diagnostics which apparently show the Kadomtsev-like reconnection patterns. To resolve this puzzle we have made a simultaneous analysis of poloidal $\mathrm{T}_{\mathrm{e}}(\mathrm{r}, \theta)$ and $q(R)$ profile evolutions. The small change of $q$ values is attributed to a flux 
conservation principle as well as to the precipitous drop of pressure gradients which drive the instability and the reconnection process.

Many valuable discussions with Drs. R. Budny, K. McGuire, W. Park, W. Stodiek, and L. Zakharov were highly appreciated. We also acknowledge skilled assistance by Mrs. W. Davis and J. Stori. The work was supported by US. Department of Energy Contract No.DE-AC02-76-CHO3073. 


\section{References}

i.J. B. Taylor, Rev. Mod. Phys. $\underline{28}, 243$ (1986)

2. E.N. Parker, "Cosmical Magnetic Fields"(Oxford:Claredon Press,'79)

3. V.M. Vasyliunas, Rev. Geophys. Space. Phys. 13, 303 (1975)

4. R. L. Stenzel and W. Gekelman, J. Geophys. Res. , $\underline{86}, 649$ (1981), W. Gekelman and H. Pfister, Phys. Fluids, 31, 2017 (1988).

5. M. Yamada, et. al, Phys. Rev. Lett., 65, 721 (1990).

6. S. von Goeler et. al. Phys.Rev.Letts.33,1201(1974); J. A. Wesson, Tokamaks (Clarendon, Oxford, 1987), pp. 176-183.

7. B. B. Kadomtsev, Sov., J. Plasma Phys., 1, 389 (1975).

8. J. A. Wesson, Plasma Phys. Contr. Fusion, 28 2 , 243, (1986)

9. F. M. Levinton et. al. Phys. Fluids, $\underline{B} 5,2554,(1993)$

10. Y. Nagayama, et. al, Rev. Sci. Instrum, 61, 3265 (1990). Y. Nagayama, et. al., Phys. Rev. Letts, 67, 3527 (1991).

11. M. Yamada, et. al., Rev. Sci. Instr. 63, 4623, (1992)

12. H. Soltwisch, Rev. Sci. Instrum, 59, 1599 (1988).

13. E. Fredrickson, Phys. Rev. Lett. $\underline{65}, 2869$ (1990).

14. F.M. Levinton, Rev. Sci. Instr. 63, 5157, (1992). F.M. Levinton, Phys. Rev. Letts., $\underline{63}, 2060$ (1989)

15. J. M. Greene, et. al., Phys. Fluids 14, 671 (1971)

16. W. Kerner, et. al., Phys. Rev. Lett. 44, 536 (1980)

17. A.J. Lichtenberg, Nucl. Fusion 24, 1277 (1984) . H. Baty, et.al. Phys. Fluids B5, 1213, (1993)

18. W.P. West et. al., Phys. Rev. Lett. 58, 2758, (1987); H. Weisen et. al. Phys. Rev. Lett. 62,434, (1989); R.C. Wolf et. al. Nucl. Fusion_33, 663, (1993); T.H. Osborne et. al. Phys. Rev. Lett. 49, 734,(1982).

19. D. Wroblewski and R. Snider, Phys. Rev. Lett. 71, 859, (1993). 


\section{Figure Captions}

Fig. $1 T_{e}(r, \theta)$ profiles in 3-D during the crash period of sawtooth. Heat transfer $\Delta T_{e}$ is superposed with coded color contours. Time step between each figure is $\sim 120$ $\mu$ sec.

Fig. 2 Heat flow contours(in color) superposed on $T_{e}(r, \theta)$ contours(solid lines) for $\mathrm{t}=216 \mu \mathrm{s}(\mathrm{a}), 314 \mu \mathrm{s}(\mathrm{b}), 368 \mu \mathrm{s}(\mathrm{c})$ and $422 \mu \mathrm{s}(\mathrm{d})$. Blue represents a heat loss of about 1 x $10^{4} \mathrm{KeV} / \mathrm{sec}$ and red a gain of $1 \times 10^{4} \mathrm{KeV} / \mathrm{sec}$. The rotation period $\tau$ is $54 \mu \mathrm{s}$. The dashed lines depict the inversion radius which is close to $q=1$ radius measured by MSE.

Fig. $3 \mathrm{q}(\mathrm{R})$ profiles derived from MSE before and after a sawtooth crash. The magnetic axis is $276 \pm 3 \mathrm{~cm}$, both from ECE diagnostics and the TRANSP analysis. The inversion radius of the ECE is about $301 \mathrm{~cm}$, which agree with the $\mathrm{q}=1$ radius from MSE, within spatial resolution.

Fig.4(a) Time evolution of central safety factor qo for a typical NBI heated L mode plasma togther with ECE based $\mathrm{T}_{\mathrm{e}}$ signal. Fig. 4(b) Synchronously co-averaged data for one sawtooth period from 9 consecutive sawteeth. The averaging time perod is $5 \mathrm{~ms}$ for each point. The crash occurs at $\mathrm{t}=0$. 


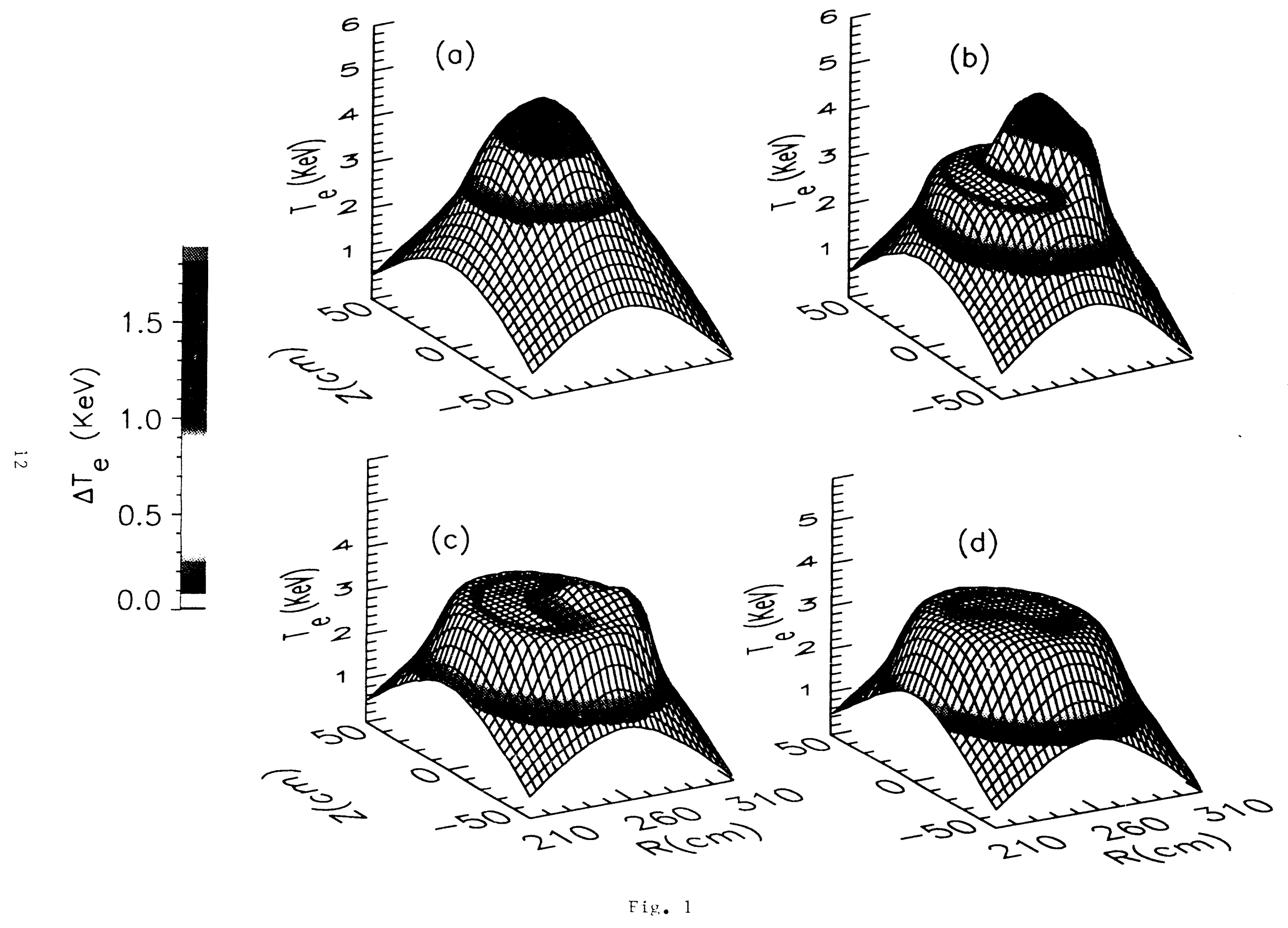



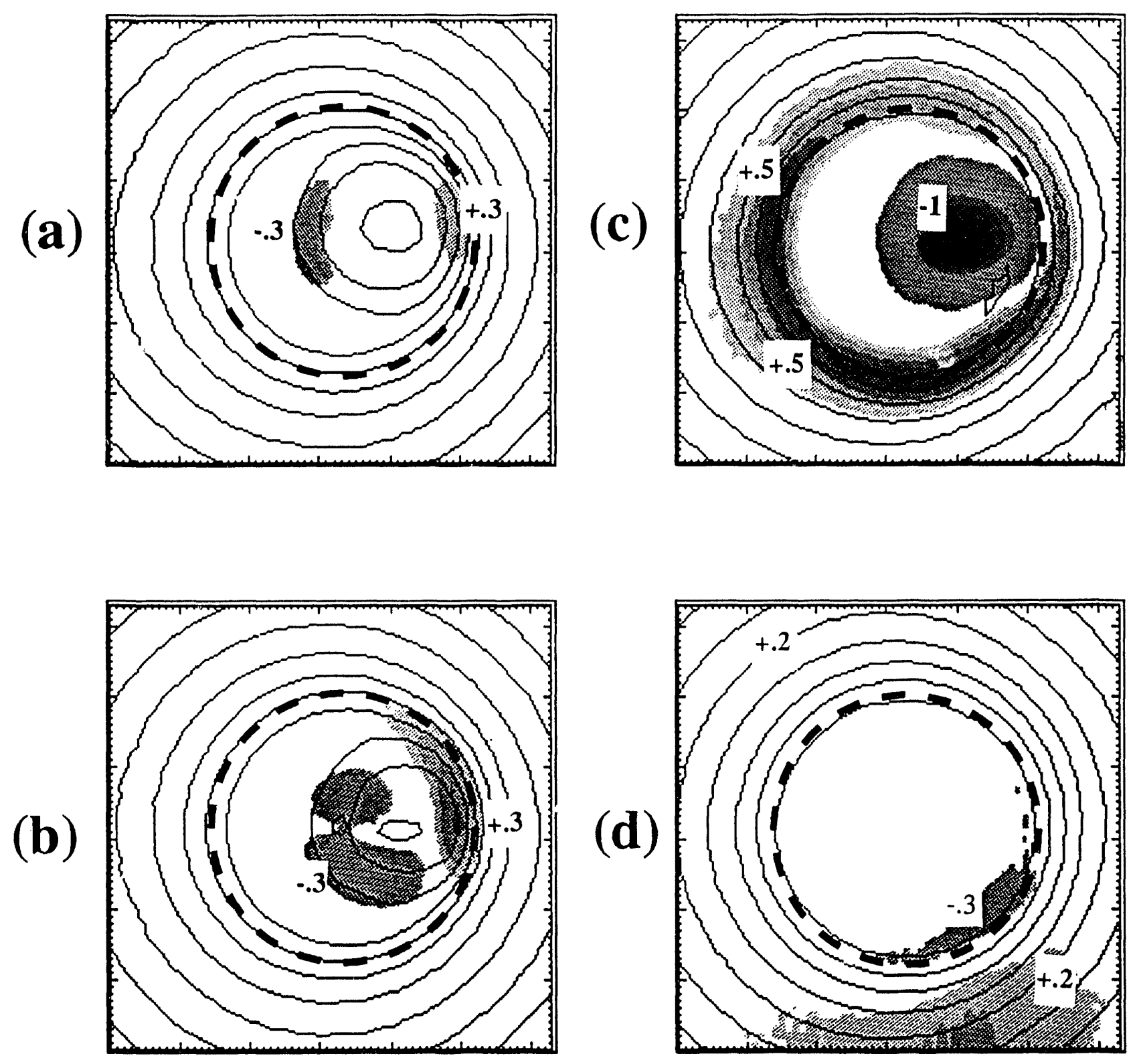

$-1 \times 10^{4} \mathrm{KeV} / \mathrm{s}$

+ 1x104 KeV/s.

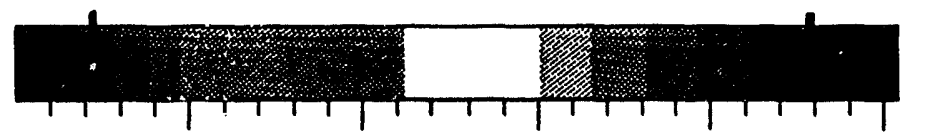

Heat

Heat

Loss

Gain

Fig. 2 


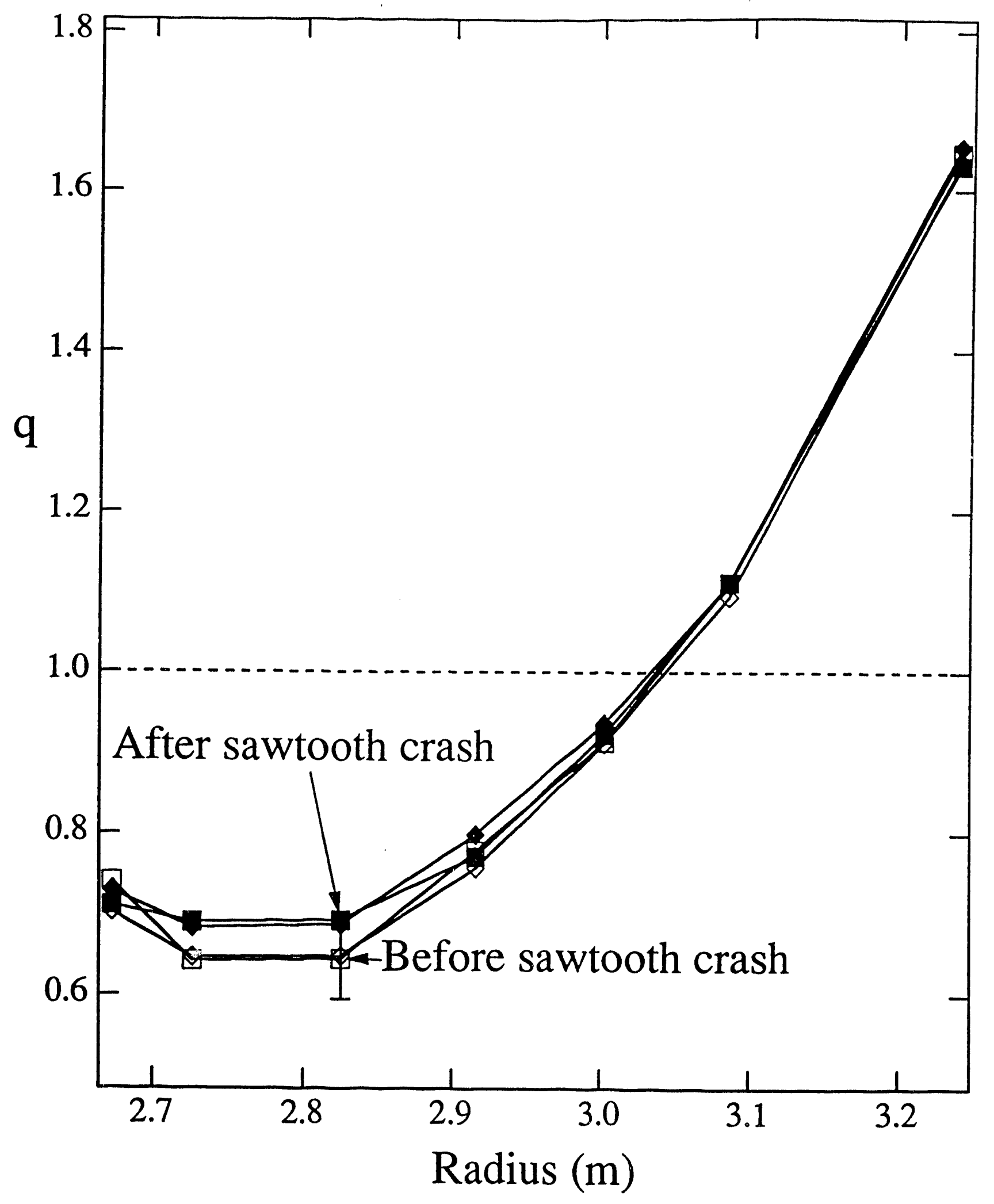

Fig. 3 

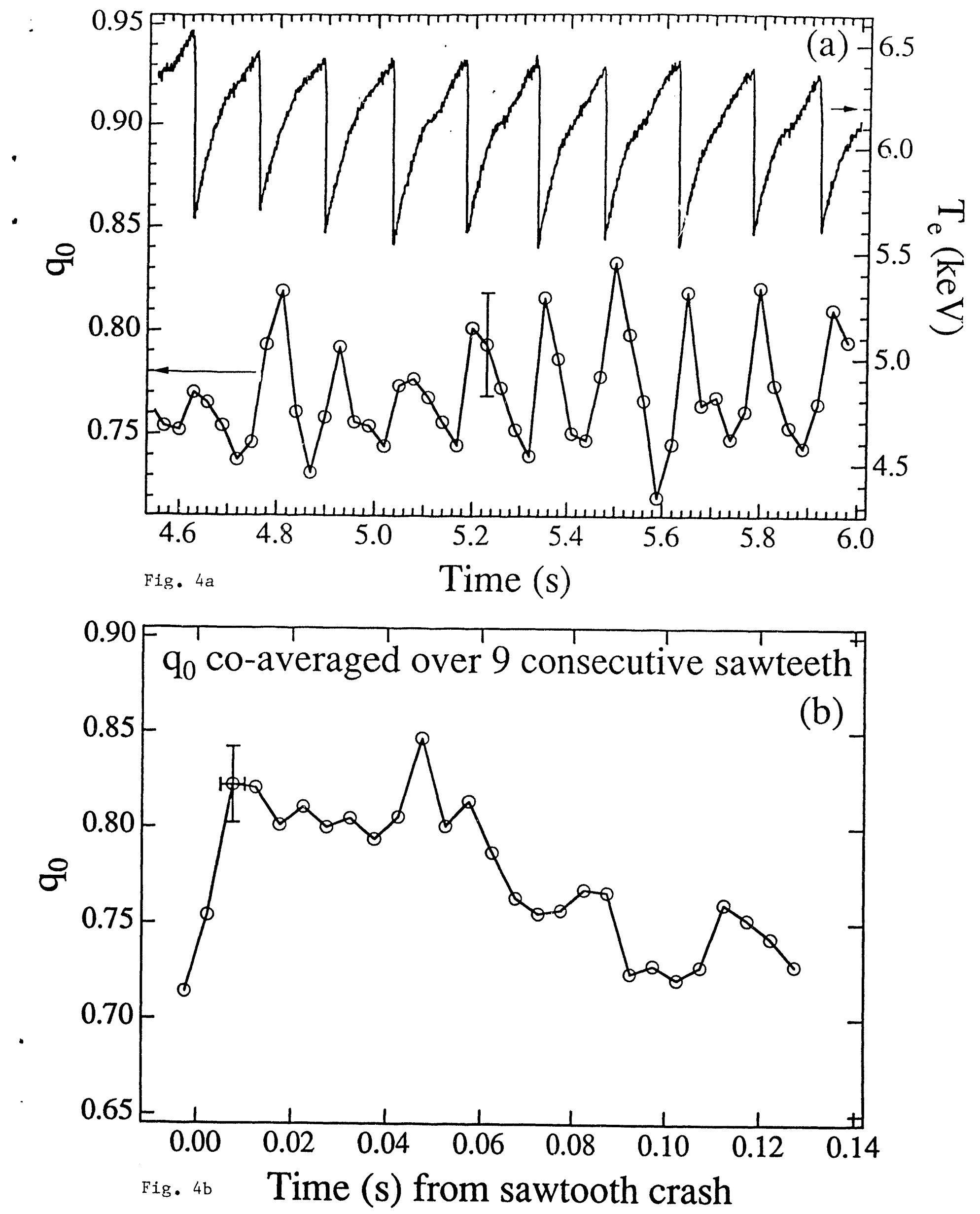


\section{EXTERNAL DISTRIBUTION IN ADDITION TO UC-420}

Dr. F. Paoloni, Univ. of Wollongong, AUSTRALIA

Prof. M.H. Brennan, Univ. of Sydney, AUSTRALIA

Plasma Research Lab., Australian Nat. Univ., AUSTRALIA

Prof. I.R. Jones, Flinders Univ, AUSTRALIA

Prot. F. Cap, Inst. for Theoretical Physics, AUSTRIA

Prof. M. Heindler, Institut für Theoretische Physik, AUSTRIA

Prof. M. Goossens, Astronomisch Instituut, BELGIUM

Ecole Royale Militaire, Lab. de Phy. Plasmas, BELGIUM

Commission-European, DG. XII-Fusion Prog., BELGIUM

Prof. R. Bouciqué, Rijksuniversiteit Gent, BELGIUM

Dr. P.H. Sakanaka, Instituto Fisica, BRAZIL

Prof. Dr. I.C. Nascimento, Instituto Fisica, Sao Paulo, BRAZIL Instituto Nacional De Pesquisas Espaciais-INPE, BRAZIL

Documents Office, Atomic Energy of Canada Lid., CANADA

Ms. M. Morin, CCFWTokamak de Varennes, CANADA

Dr. M.P. Bachynski, MPB Technologies, Inc., CANADA

Dr. H.M. Skarsgard, Univ. of Saskatchewan, CANADA

Prof. J. Teichmann, Univ. of Montreal, CANADA

Prof. S.R. Sreenivasan, Univ. of Calgary, CANADA

Prof. T.W. Johnston, INRS-Energie, CANADA

Dr. R. Bolton, Centre canadien de fusion magnétique, CANADA

Dr. C.R. James,. Univ. of Alberta, CANADA

Dr. P. Lukác, Komenského Universzita, CZECHO-SLOVAKIA

The Librarian, Culham Laboratory, ENGLAND

Library, R61, Rutherford Appleton Laboratory, ENGLAND

Mrs. S.A. Hutchinson, JET Library, ENGLAND

Dr. S.C. Sharma, Univ. of South Pacific, FIJI ISLANDS

P. Mähönen, Univ. of Helsinki, FINLAND

Prof. M.N. Bussac, Ecole Polytechnique., FRANCE

C. Mouttet, Lab. de Physique des Milieux lonisés, FRANCE

J. Radet, CEN/CADARACHE - Bat 506, FRANCE

Prof. E. Economou, Univ. of Crete, GREECE

Ms. C. Rinni, Univ. of loannina, GREECE

Preprint Library, Hungarian Academy of Sci., HUNGARY

Dr. B. DasGupta, Saha Inst. of Nuclear Physics, INDIA

Dr. P. Kaw, Inst. for Plasma Research, INDIA

Dr. P. Rosenau, Israel Inst. of Technology, ISRAEL

Librarian, Intemational Center for Theo Physics, ITALY

Miss C. De Palo, Associazione EURATOM-ENEA, ITALY

Dr. G. Grosso, Istituto di Fisica del Plasma, ITALY

Prof. G. Rostangni, Istituto Gas Ionizzati Del Cnr, ITALY
Dr. H. Yamato, Toshiba Res \& Devel Center, JAPAN

Prof. I. Kawakami, Hiroshima Univ., JAPAN

Prof. K. Nishikawa, Hiroshima Univ., JAP.AN

Librarian, Naka Fusion Research Establishment, JAERI, JAPAN

Director, Japan Atomic Energy Research Inst., JAPAN

Prof. S. Itoh, Kyushu Univ., JAPAN

Research Info. Ctr., National Instit. for Fusion Science, JAPAN

Prof. S. Tanaka, Kyoto Univ., JAPAN

Library, Kyoto Univ., JAPAN

Prot. N. Inove, Univ. of Tokyo, JAPAN

Secretary, Plasma Section, Electrotechnical Lab., JAPAN

S. Mori, Technical Advisor, JAERI, JAPAN

Dr. O. Mitarai, Kumamoto Inst. of Technology, JAPAN

Dr. G.S. Lee, Korea Basic Sci. Ctr., KOREA

J. Hyeon-Sook, Korea Atomic Energy Research Inst., KOREA

D.I. Choi, The Korea Adv. Inst. of Sci. \& Tech., KOREA

Prot. B.S. Liley, Univ. of Waikato, NEW ZEALAND Inst of Physics, Chinese Acad Sci PEOPLE'S REP. OF CHINA Library, Inst. of Plasma Physics, PEOPLE'S REP. OF CHINA Tsinghua Univ. Library, PEOPLE'S REPUBLIC OF CHINA Z. Li, S.W. Inst Physics, PEOPLE'S REPUBLIC OF CHINA Prof. J.A.C. Cabral, Instituto Superior Tecnico. PORTUGAL Prof. M.A. Hellberg, Univ. of Natal, S. AFRICA Prof. D.E. Kim, Pohang Inst. of Sci. \& Tech., SO. KOREA Prot. C.I.E.M.A.T, Fusion Division Library, SPAIN Dr. L. Stenflo, Univ. of UMEA, SWEDEN Library, Royal Inst. of Technology, SWEDEN Prof. H. Wilhelmson, Chalmers Univ. of Tech., SWEDEN Centre Phys. Des Plasmas, Ecole Polytech, SWITZERLAND Bibliotheek, Inst. Voor Plasma-Fysica, THE NETHERLANDS Asst. Prof. Dr. S. Cakir, Middle East Tech. Univ., TURKEY Dr. V.A. Glukhikh,Sci. Res. Inst. Electrophys.I Apparatus, USSR Dr. D.D. Ryutov, Siberian Branch of Academy of Sci., USSR Dr. G.A. Eliseev, I.V. Kurchatov Inst., USSR Librarian, The Ukr.SSR Academy of Sciences, USSR Dr. L.M. Kovrizhnykh, Inst. of General Physics, USSR Kernforschungsanlage GmbH, Zentralbibliothek, W. GERMANY Bibliothek, Inst. Für Plasmaforschung, W. GERMANY Prof. K. Schindler, Ruhr-Universitát Bochum, W. GERMANY Dr. F. Wagner, (ASDEX), Max-Planck-Institut, W. GERMANY Librarian, Max-Planck-Institut, W. GERMANY 

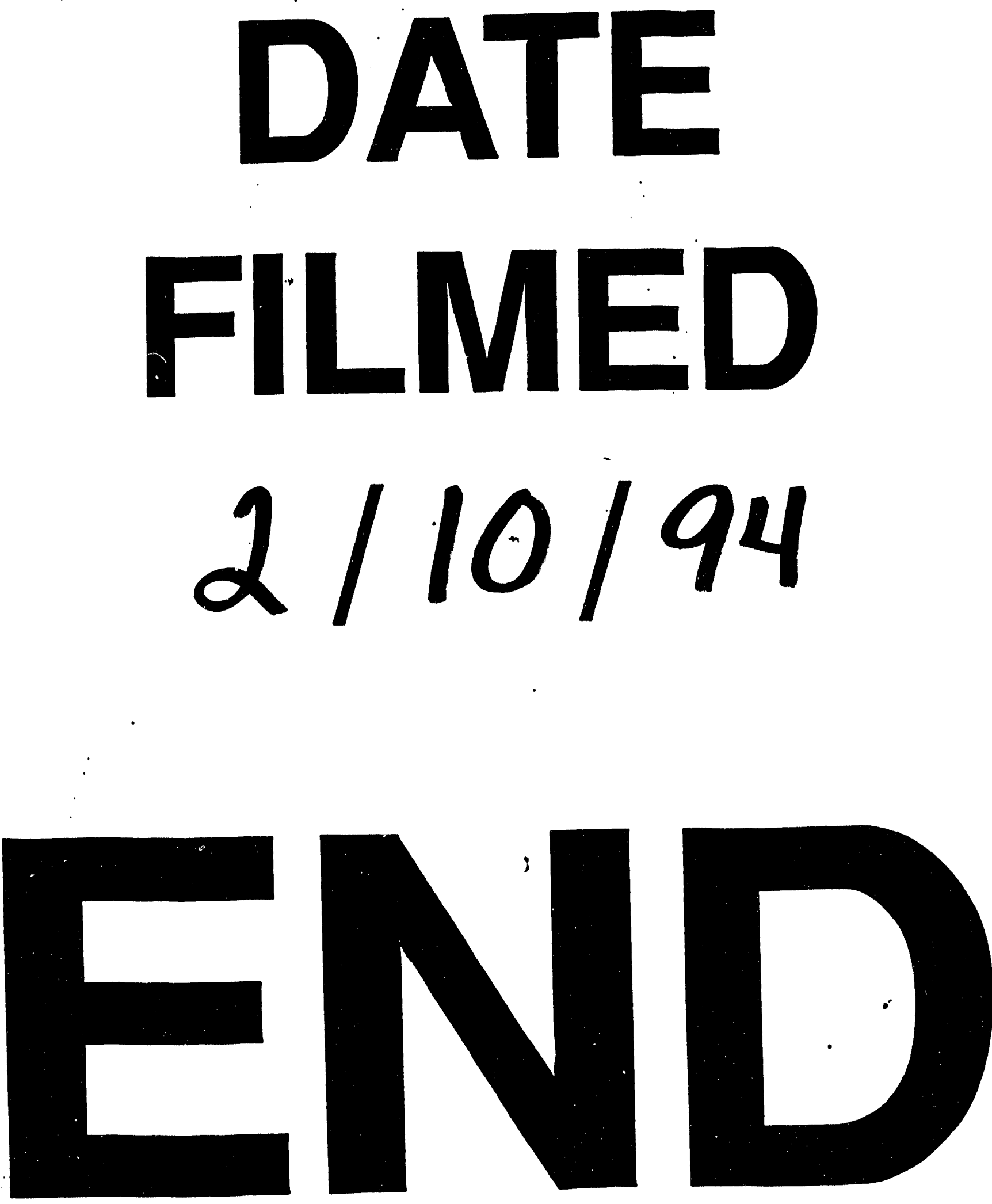
